Military Technical College Kobry El-Kobbah, Cairo, Egypt

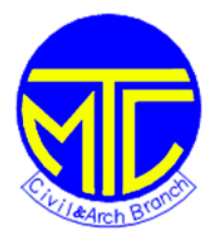

\title{
Interior Architecture: Design flexibility enabling maintenance of research labs services with minimum disruption of ongoing researches
}

$$
\text { By }
$$

Dr. Ahmed Aly-Kamel ElDib*

\section{$\underline{\text { Abstract: }}$}

This paper - through averment of "Interior Architecture" role "소 one of the accurate specializations for completing the Architectural Sciences" - discusses the "flexibility in design" needs for "open labs layout". This type of "Laboratories Layouts" stimulates sharing of resources that are becoming the norm, speeding-up research process, leading to the production of more discoveries

A proposed design technique concept, focuses upon operating problems concerned with frequent maintenance and replacement of laboratory services \& supplies (such as electrical / A/C \& filtering units / lighting / . . etc.).

The proposed design concept is designated for lab areas in need for constant high level of "dust-free" and "sterilized" enclosure zones. The importance of preservation efficacy represents an exigency for interior environmental requirements enclosure sustainability for these types of lab areas (e.g., special degree of electronics and bio labs, such as "BSL-4"). The operations of maintenance and replacement, can thus be done with "almost" no disruption of under going researches.

\section{Keywords:}

Interior Architecture, Design Flexibility, research laboratories

* - EAEA (Egyptian $\underline{\text { Atomic }} \underline{\text { Energy }} \underline{\text { Authority) }}$

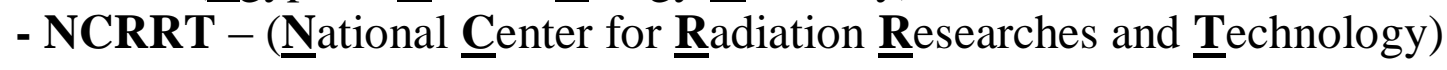

- Irradiation Engineering Dept. 


\section{Introduction:}

A new concept of laboratory design is emerging in order to create lab environments that are responsive to present needs, and capable of accommodating future demands. Some institutions may on average, change up to 11 percent of their spaces in this way each year. Changes in research activities, and ways in which they are performed, may require the construction of a new facility and/or the relocation of people and equipment to that location. Facing these problems lies in maximizing flexibility, which means the reduction of significant renovation or new construction in order to accommodate these "new" changes.

The design concept discussed in this paper, is claimed to be appropriate for application to designated research areas, particularly, with disciplines in need of special environmental requirements, such as; Microbiology, Electronics research and/or manufacturing, as well as some branches of Physics research, and Chemistry, ...etc.

The suggested design concept aims at:-

a) Protection from potential "cross - contamination" generated by the ongoing research procedures and works upon the facility and surrounding environment.

b) Protection of the laboratory environment from outside factors (e.g., airborne pollution, . etc.) which have a negative influence upon research work outcome.

\section{$\underline{\text { 2. Previous work survey examples }}$}

\section{Case study $1(*$ Ref-1/p195)}

Heritage Medical Research Building - University of Alberta, Canada

Architects: Woolfenden Hamilton Brown

- All laboratory spaces have full services available. Upon applying the 'renovation' requirement, each laboratory module should be able to undergoing renovation without infringing upon another - the concept of external servicing via an atrium on each side of the building was introduced.

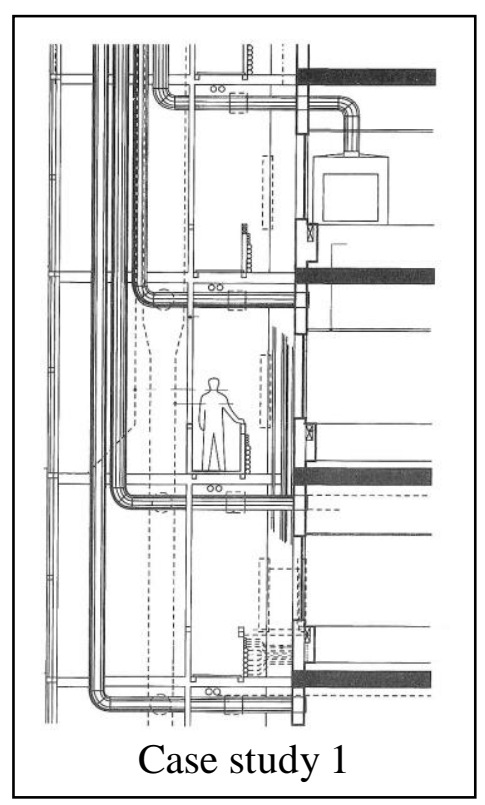


Case study 2 (*Ref-1/p235)

Biomedical Building - Australian Technology Park (ATP, Sydney) Architects TGP Architects \& Planners

- The Building was designed for extreme adaptability, and designed to enable the reticulation of a high level of engineering services.

- Hinged panels between windows provide external access to services in the vertical ducts and spandrels for maintenance or modification, without loss of integrity of the occupied

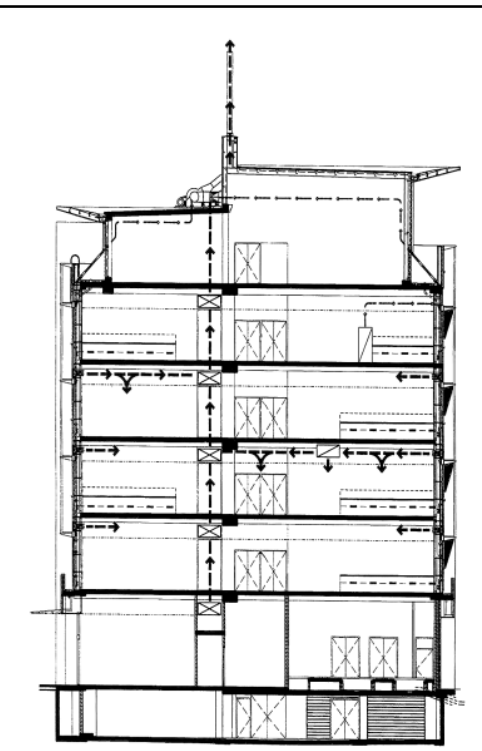

Case study $2 b$

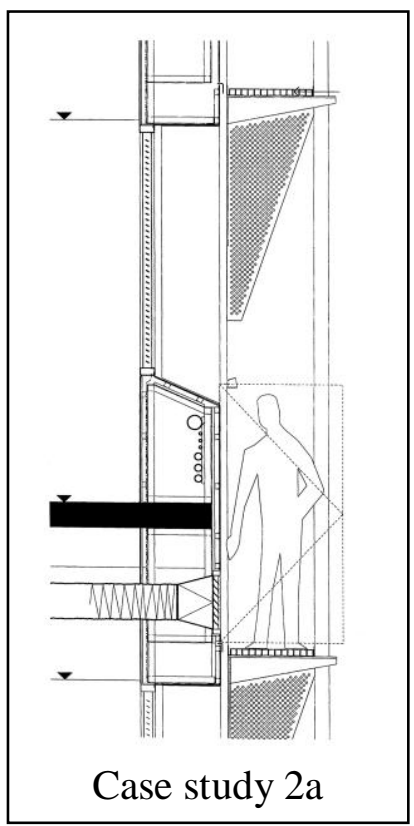
laboratory spaces.

\section{Case study 3 (*Ref-1/p253)}

Laboratory Design Competition at the University of Queensland, Australia Architects: Peddle Thorp Architects and Donovan Hill Architects

Laboratory consultant: Brian Griffin

The laboratories are generic, adaptable and not specific. The interstitial space between laboratory floors is accessible from a linear plant room at each level, extending the full length of the building and accommodating the several air handling units for each zone, distribution boards, control valves, compressors, vacuum pumps, transformers and other small plant.

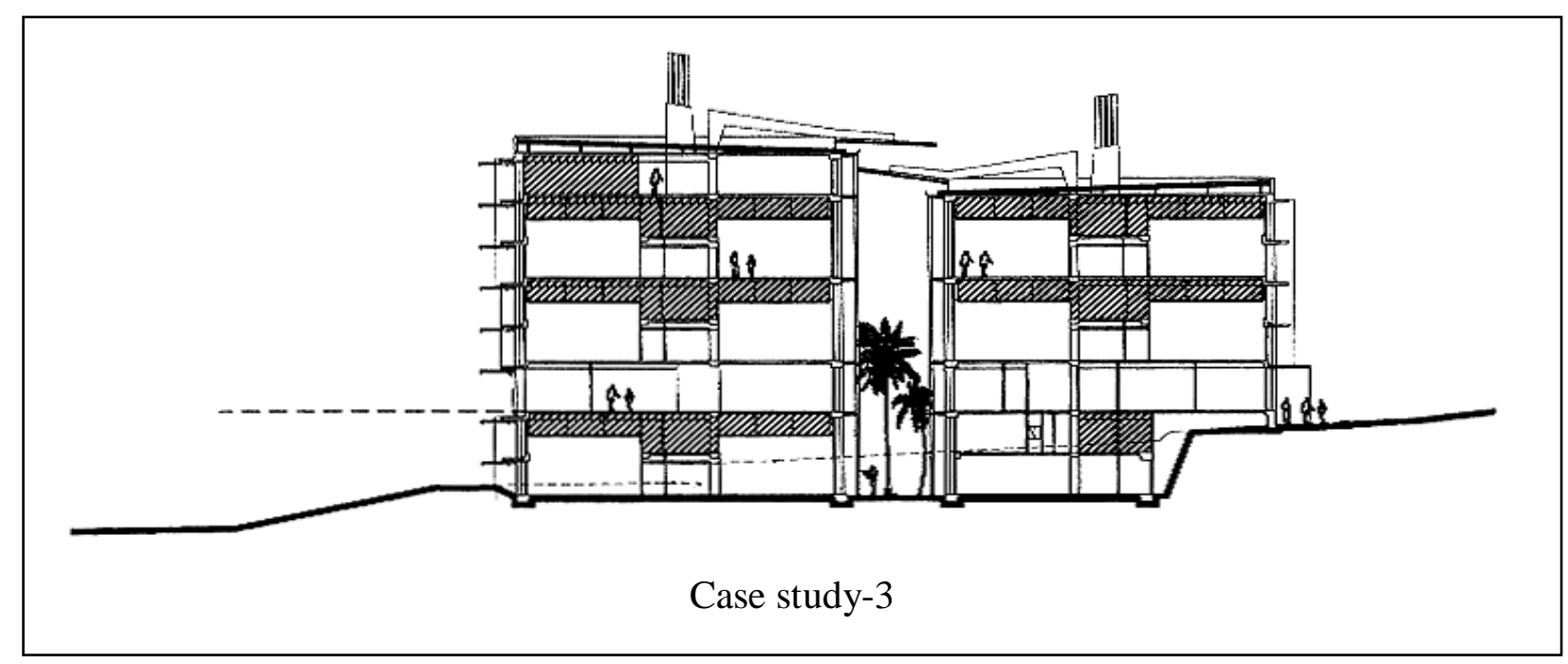




\section{Case study A-4 (*Ref-1/p313)}

James H Clark Center - Stanford University - California, USA

Principal architects: MBT Architecture / Design architects: Foster \& Partners

Laboratory design: MBT Architecture

Forty-five research groups from biology, engineering, physics, chemistry, mathematics and medicine work collaboratively in a unique environment.

- The structural concept for the building supports envisages that the building to be open to encourage interaction.

- Within the vertical dimension the floor-plate itself could be column free allowing free space which could suit a variety of needs and be adaptable in the future.

- The provision of services to multiple functions on the floor-plate with a variety of layouts necessitated that the services come from above. A system of accessible utilities at the ceiling was developed as part of this strategy.

- The castellated or cellular steel beams are 1-m deep and allows the mechanical ducts to pass through the webs of the beams and girders, thus saving overall system depth.

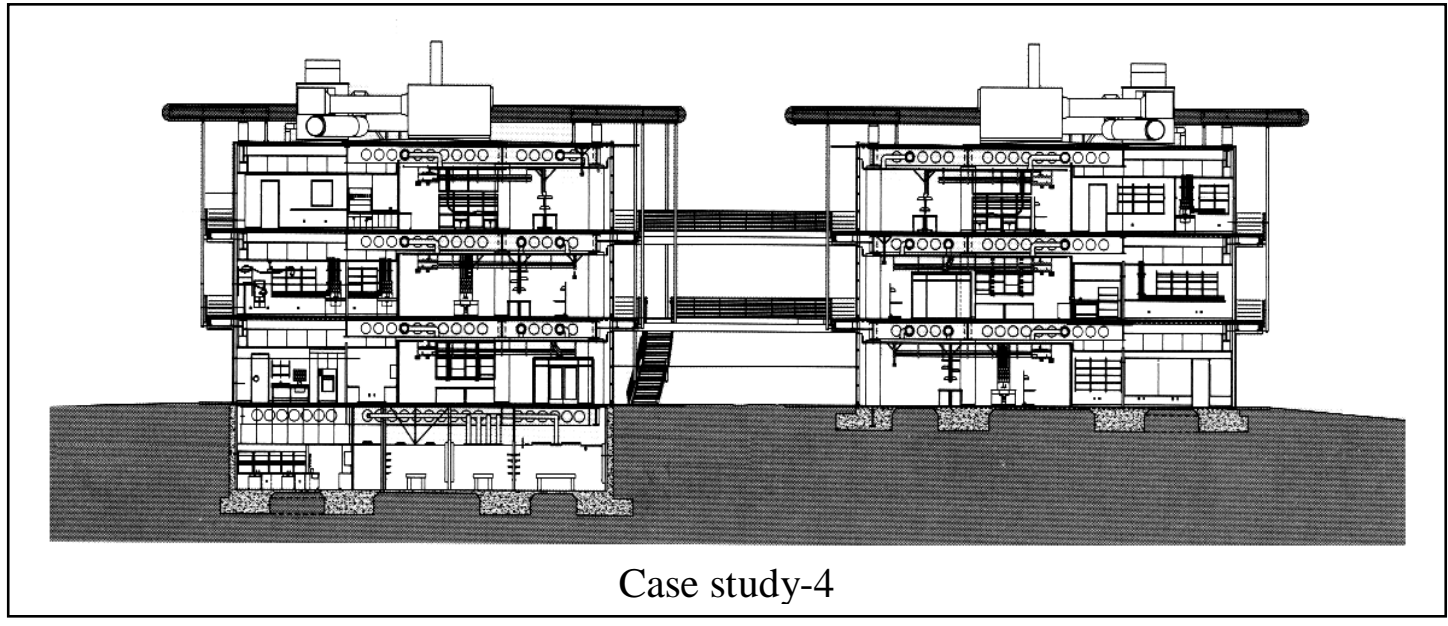

Case study 5 (*Ref-2/p13)

Technology Enhanced Learning

Center, State University of west

Georgia Carrolton, USA

"Perkins \& Will architect

"Overhead service carriers" for easy connection and disconnection of engineering services allows for ready reconfiguration of the laboratory.

Overhead service carriers

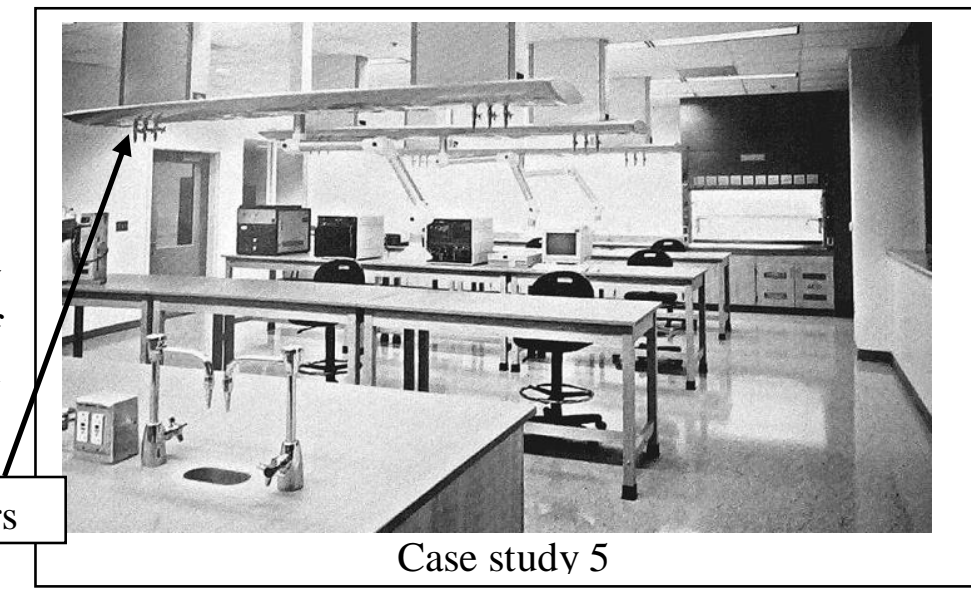


Case study $6(* \operatorname{Ref-2/p31)}$

(College of Medicine, Northwestern University, Evanston, Illinois - "Perkins \& Will, architect") Laboratory bench services are supplied from the ceiling directly to the bench by shaft.

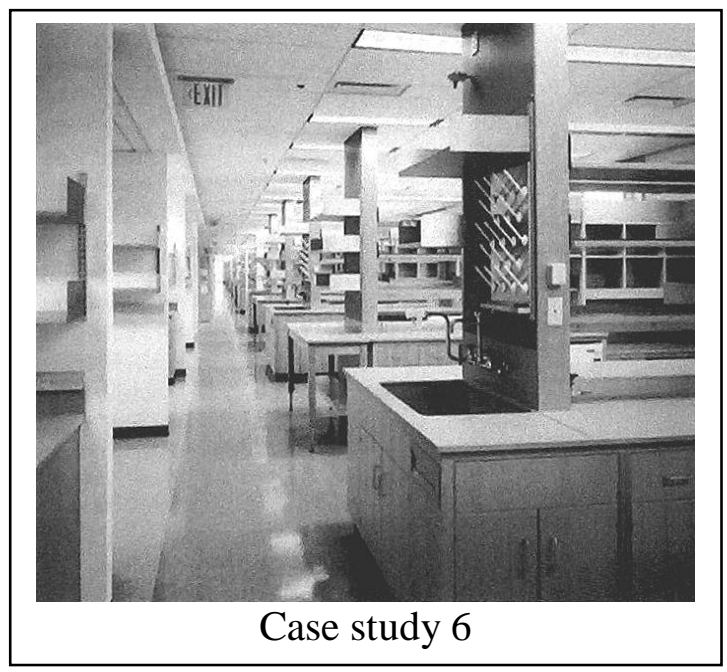

\section{Case study 7 (*Ref-2/p209)}

(NIH Building 40, Bethesda, Maryland. - "HLM, architect")

- Service Floor (or Interstitial Space): Services are dropped down into the laboratory.

- Advantages: The use of interstitial space allows the building to accommodate change very easily and gives it a longer useful life. The laboratories are unobstructed by shafts and can be renovated quickly, cheaply and with very little (if any) interruption. The system is cost effective over

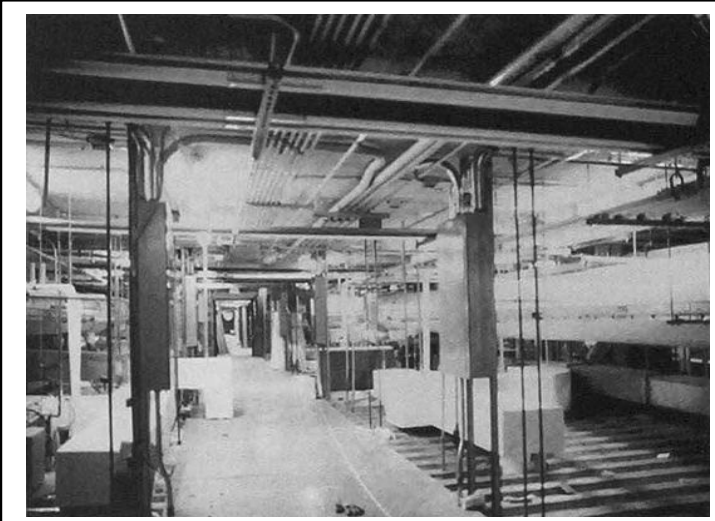

Case study $7 \mathrm{a}$ the life of the building if the laboratories will have to be renovated at least every five to ten years.

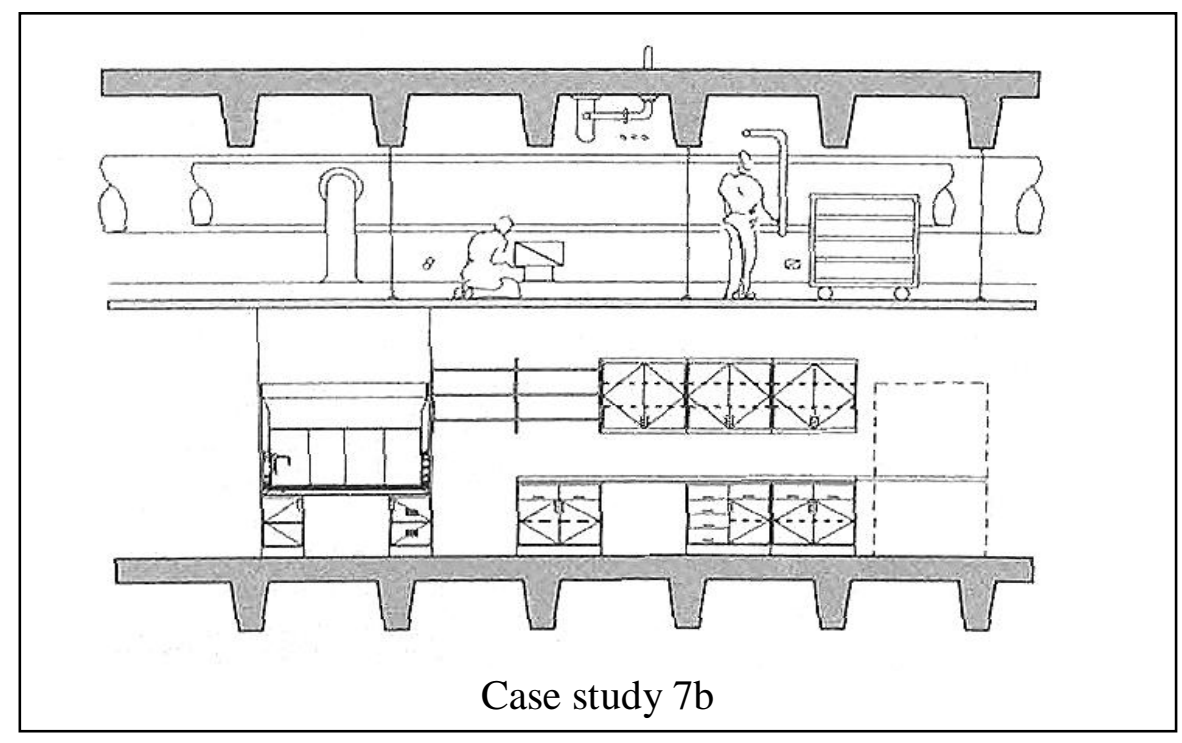




\section{$\underline{\text { 3.Suggested Construction concept }}$}

The technique suggested, is a "mesh" of crossing beams (concrete construction ${ }^{*-1}$ ). The purpose of this choice is to create interior lab layouts, unobstructed by columns.

There are two types of levels, in which each have a particular construction method;

a) The laboratory level, "a mesh" of crossing beams (Fig 1), supporting a concrete slab, in which will be the laboratory level.

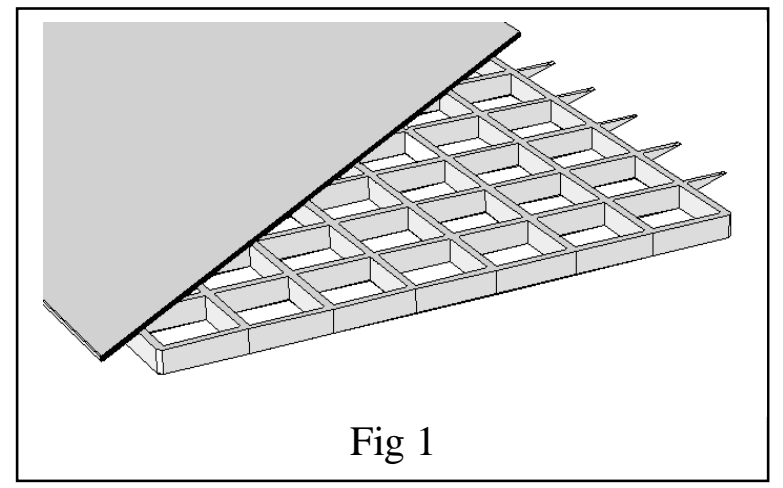

b) Above the laboratory level, lies the "Service level", another "mesh" of crossing beams, but they differ from those of the laboratory level, that each beam has its cross section shaped as an inverted letter " $T$ " (Fig 2)

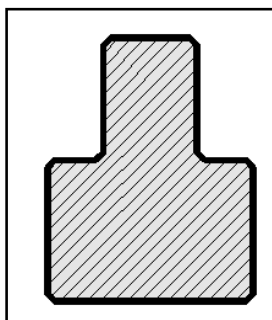

Fig 2

This mesh of crossing beams (item $b$ )-) forms "hollow squares", which will embrace a semi-

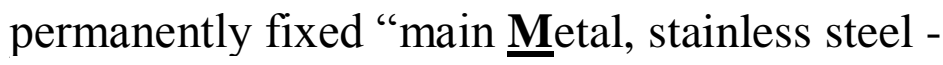
Hollow $\underline{B}$ oxes" (MHB) (Figs 3a \& 3b).

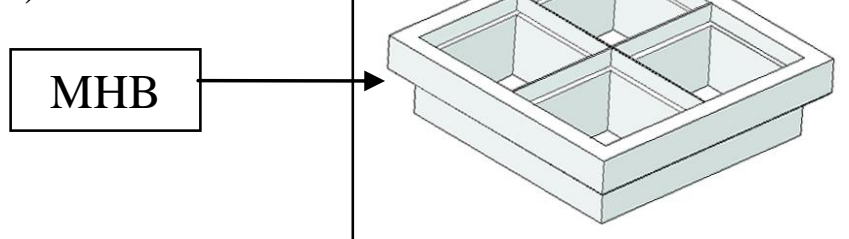

Fig 3a

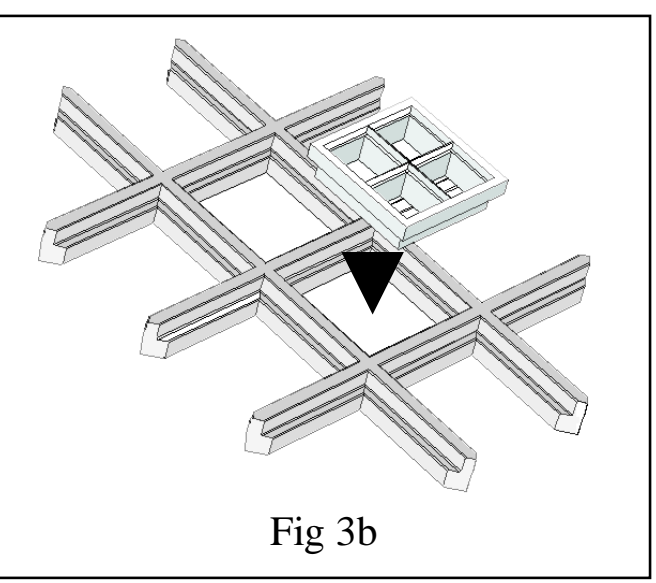

Fig $3 b$

Each of these boxes (MHBs), will be a "reception pot" for the supply services. It will facilitate manipulation of supplying services and maintenance operations. The paper focuses, exclusively, upon two of these service means, where maintenance and/or replacement works are enabled to take place with no disruption of ongoing research in the laboratory level.

*-1 NOTE: - The concrete structure can be replaced with steel structure depending on cost effectiveness 
These services and supply means are: -

- "Lighting"

- "Ventilation and Air Conditioning"

- Plus "Auxiliary service means and tools", include: -

-"Winch's crane", its "car" and "railway"

- "Metal Arcades".

Section "8)" of this paper presents sequential steps for maintenance and servicing process. It will show how the system design concept fulfills the enclosure sustainability requirements for these types of plants, with no disruption of ongoing researches in laboratory areas

\section{4) Lighting}

\section{4-1) Initial hint:}

Initially, two common methods are used in laboratory environments to produce ambient (general) lighting, as follows:-

1. "Direct distribution" (Fig-4) or "down-lighting", lets researchers perform their tasks encountering harsh shadowing or high contrast from one work zone to next.

2. "Indirect/direct distribution" (Fig-5), a combination of "down-lighting" and "uplighting" of the ceiling surface, includes a substantial reduction of distracting shadows over work surfaces and an increased sense of brightness without overlighting the space.
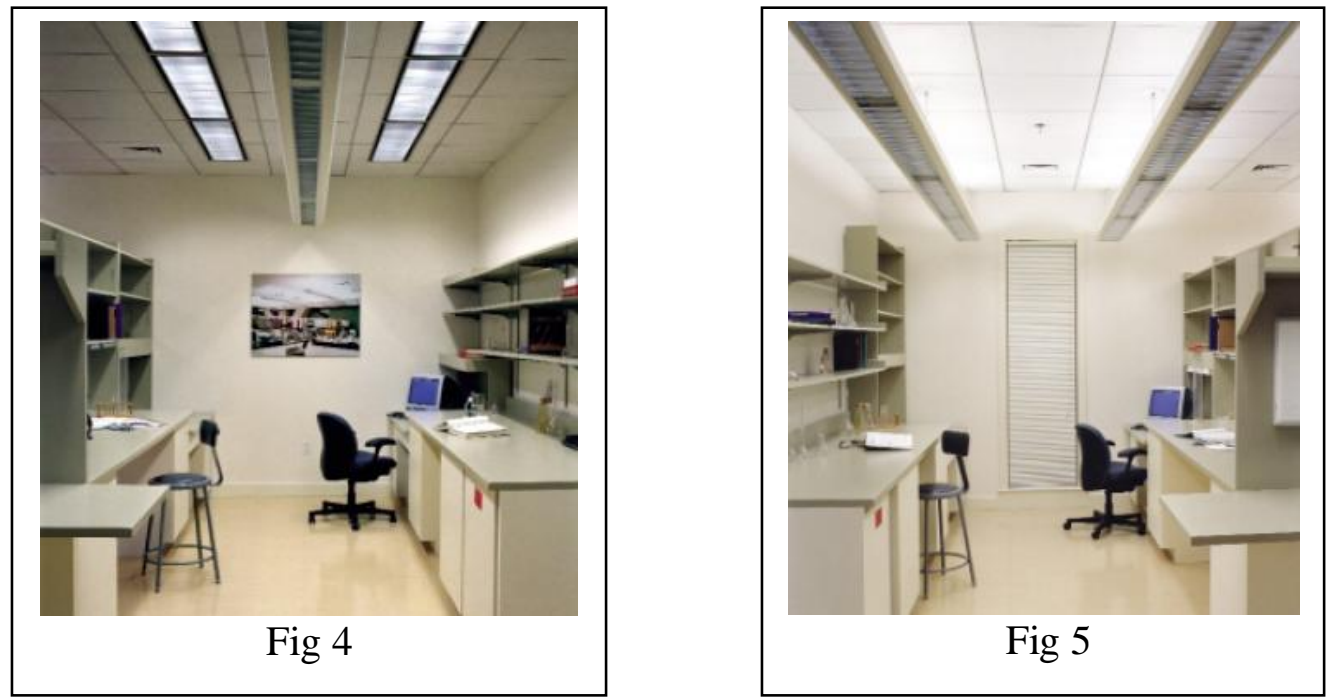

\section{4-2)"Light fixture"(LF) using "Indirect/direct distribution" method:}

The (LF) consists of two main parts, Fig 6 shows how it fits into the (MHB) unit.

"Fixed part" (PL-1) is firmly implicated (almost immobile), within the main metal box (MHB). 
The"PL-1" acts as a "receiver pot" for the movable part (PL-2) embracing all replaceable parts of the light unit (LF). Concerning part (PL1) (Fig 7), a transparent "glass box" is permanently attached firmly beneath it. Its outer surface is in direct contact with the interior enclosure atmosphere of the lab, taking the role of "environmental barrier" between both laboratory Level enclosure and, service-level environment.

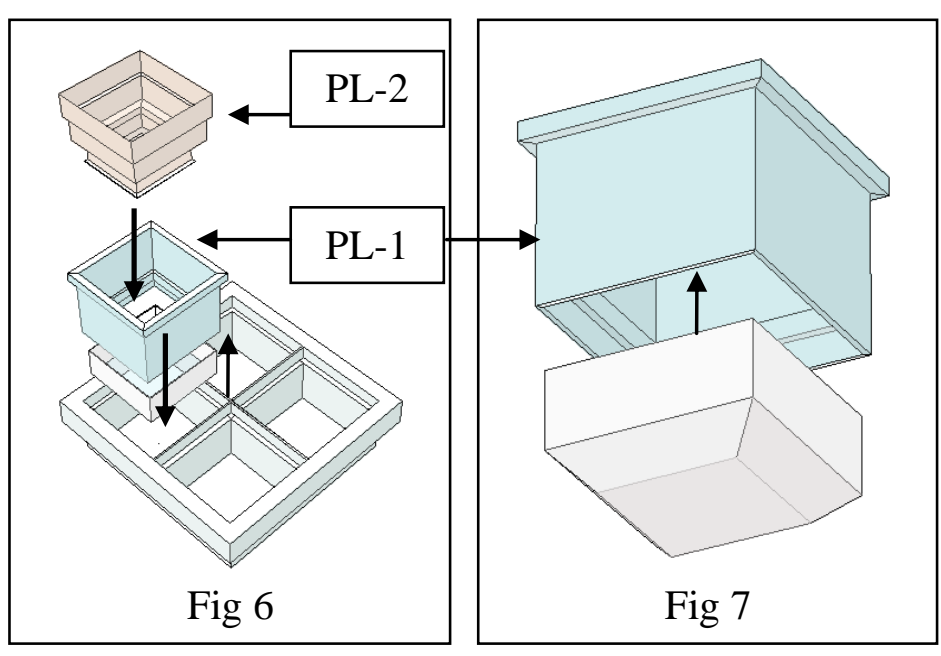

On the other hand, the movable part (Fig 8) can be replaced "completely" or "partially". The reflectors of the light unit are fixed in part (PL-2), embracing the lamps are designed so that the different angles of light reflection simulate "Indirect/direct" distribution of light into the laboratory environment.

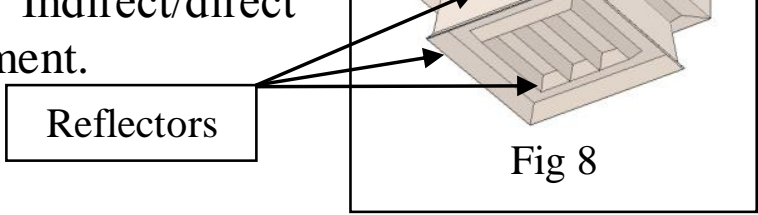

Thus, the (LF) procure the ability of maintenance and service procedures, totally, with no disruption of ongoing researches or destitution of laboratory environmental enclosure conditions

\section{5) Ventilation, Air Conditioning and Filtration (VAF) unit}

The (VAF) unit, consists four part types (Fig 9);-

a) The "Fixed part" (VC-1), acts as a "receiver pot" for three replaceable parts

b) These three parts are: Carbon filter, HEPA filter and, Nano filter. A special "hut" is fixed above (VC-1) and connected by a flexible duct to the main ducting system The (VC-1) consists beneath it, a group of a "ĹLongitudinal Flapping Blades"- or "LFBs" (Fig 10), where their control mechanism lies above the (VC-1) unit. When the (VAF) unit is operational the "LFBs" are in the "open state" (Fig 11), permitting filtered air, supplied from the main $\mathrm{A} / \mathrm{C}$ ducting system, to pass through the filters, penetrating into the laboratory environment.

This is realized without enclosure destitution of atmospheric interior conditions. The blades are turned into "closed state" (Fig 12) when the maintenance or replacement 
operation of Movable parts are taking place.
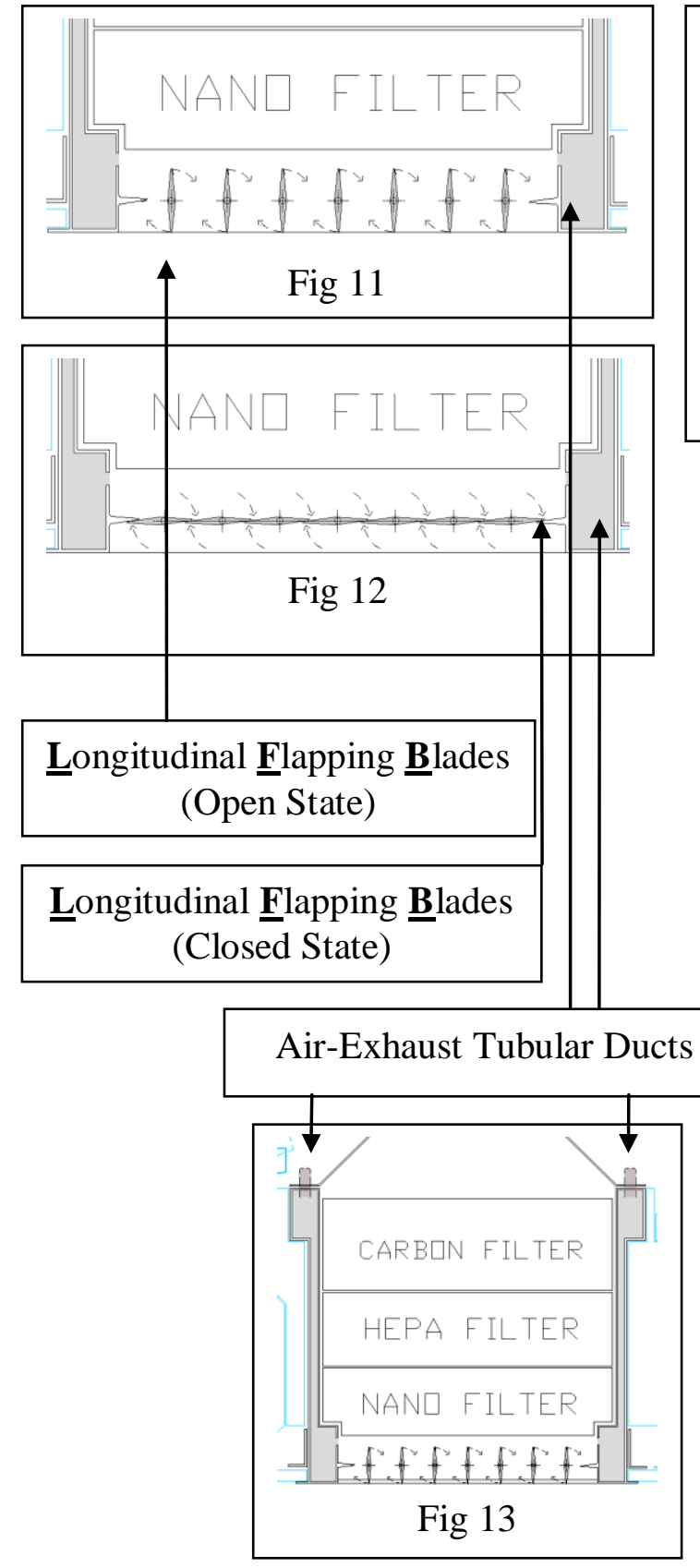

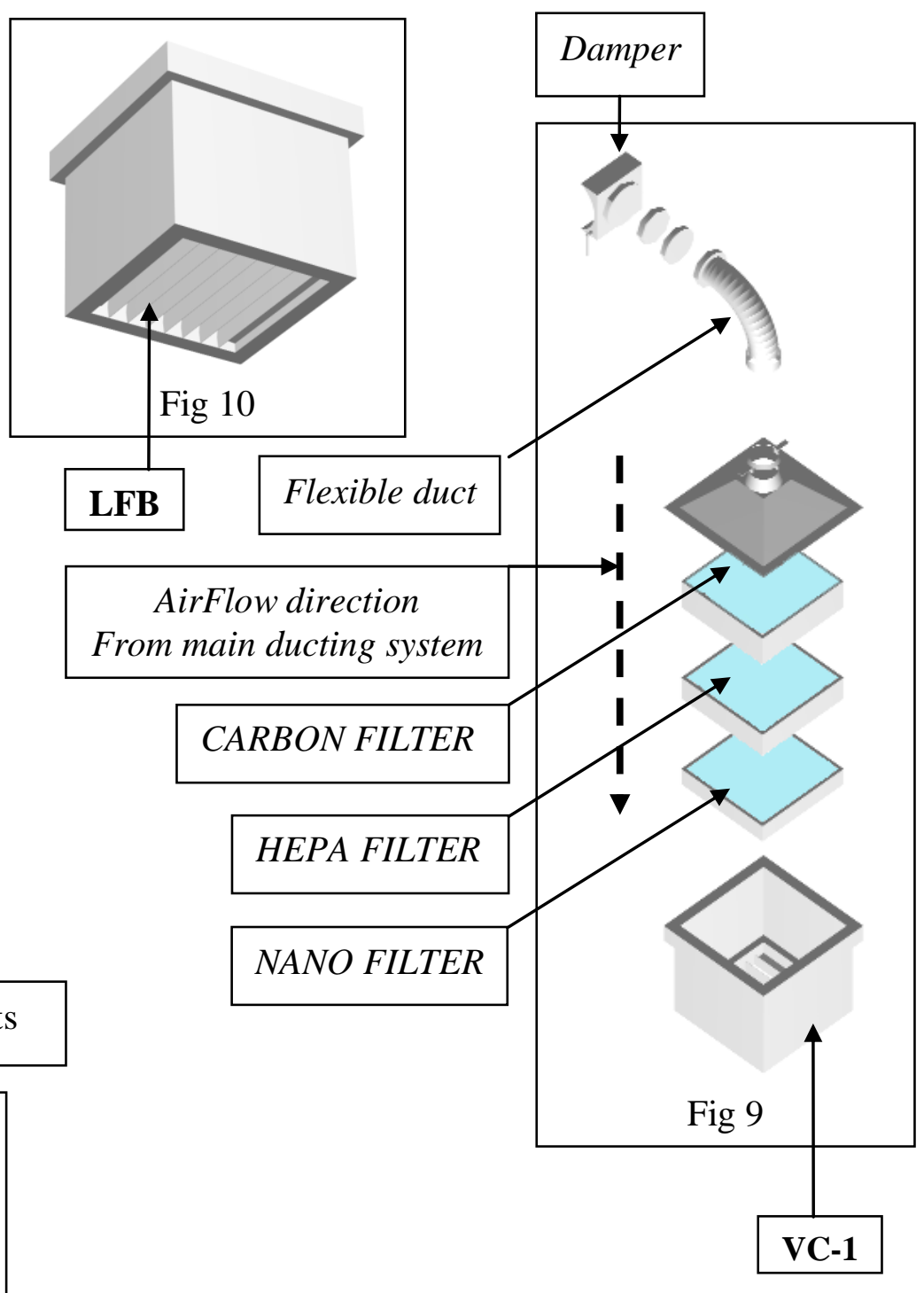

There is an "Air-Exhaust Tubular Ducts" included in (VC-1) unit (Fig 13), to "suck" the air above the "LFB" area. These ducts create a negative air pressure zone, preventing any chance of unfiltered air to penetrate into laboratory interior environment during servicing and replacement operations.

After the "LFB" blades are reputed into the "open state", the "Tubular Ducts" are off duty, after completion of maintenance operations. 
Thus, The (VAF) unit procures, as well as the (LF), the dealing with maintenance and service operation, totally with no disruption of ongoing researches, preserving laboratory environmental enclosure conditions level.

\section{6) Winch's crane, its car and railway as a Transportation means}

There is a "railroad" (Fig 14) hanged from the above "mesh" of crossing beams supporting the slab of the laboratory level above. By its turn, a "hanged" car attached to the winch crane, going back and forth along the "railway", in order to assist maintenance works needed.

The winch crane is able of performing "amendable" lateral moves to adapt its correct position for lifting and transporting operations needed in the maintenance

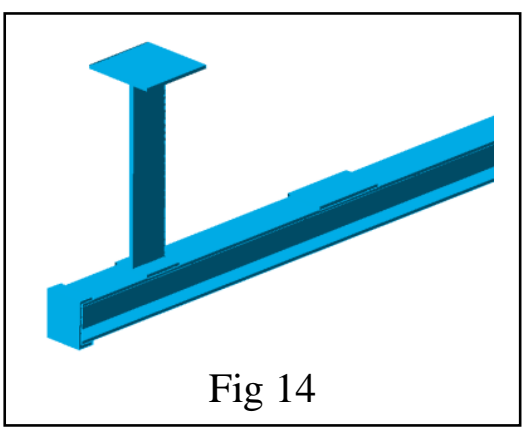
procedures without having collision with any other installed items (e.g., flexible ducts) (Figs 15, 16)
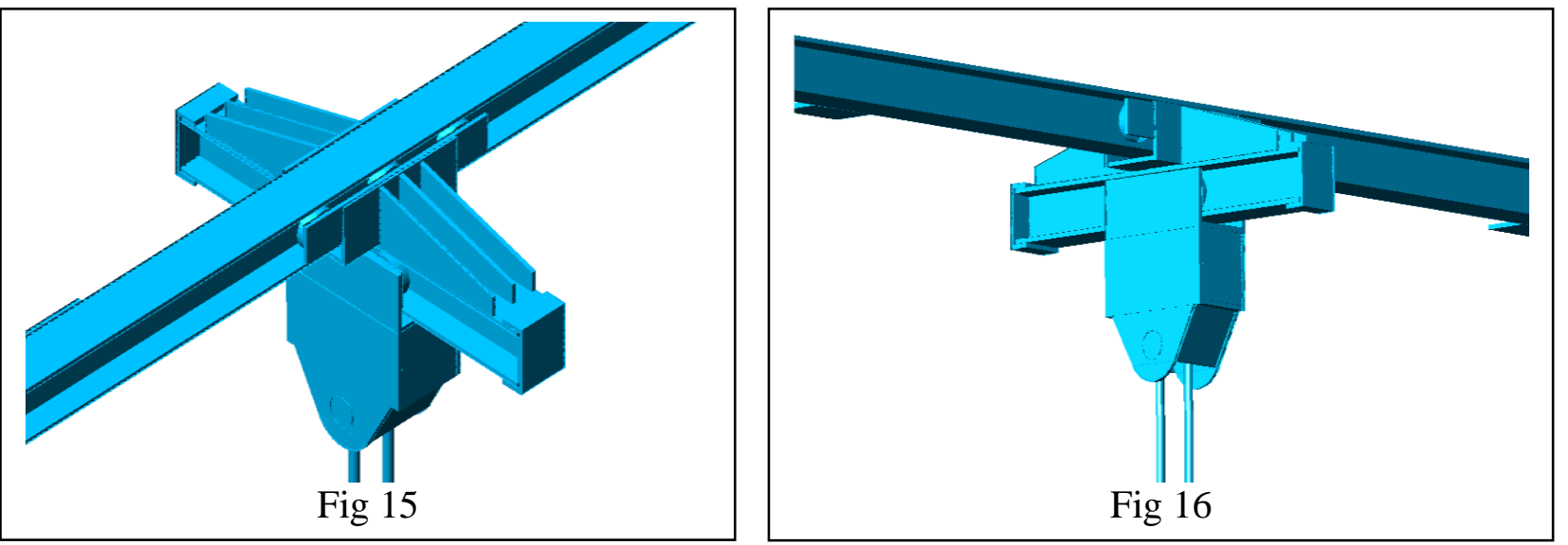

\section{7) Metal Arcades walkways}

- Metal Arcades, fixed above "crossing-beams" (Figs 17, 18), create walkways to ease the maintenance staff performing their duties.
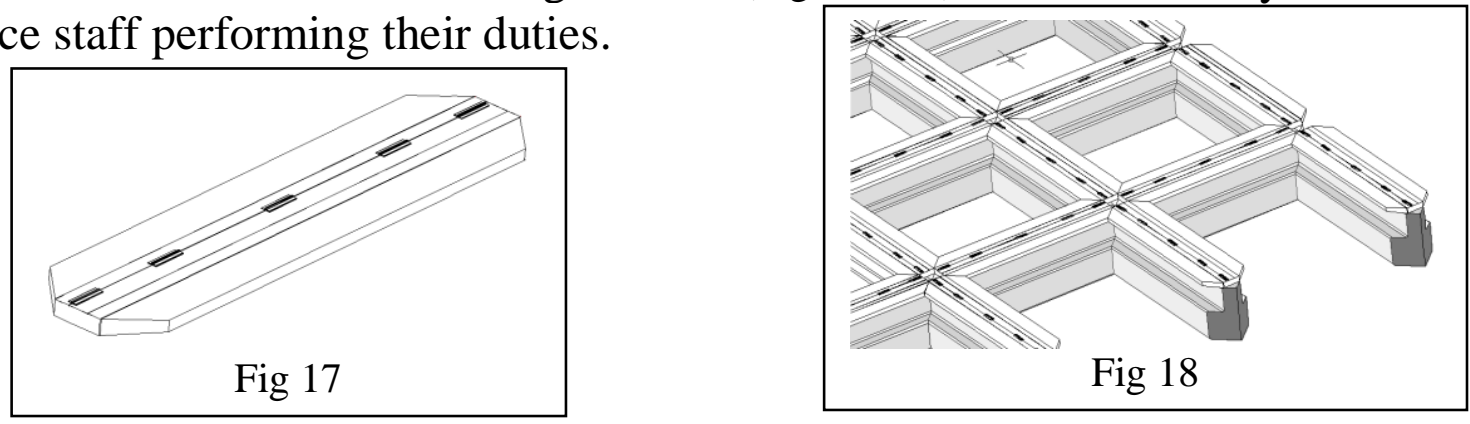
At the same time these "arcades" conserve mainly:-

- "PVC-U" plastic sheathing for power and control wiring

- "Air-exhaust pipes", having valves in selected locations, suitable to be connected to each "AirExhaust Tubular Duct" included in (VC-1) unit embraced by the (VAF) unit. (Figure 19)

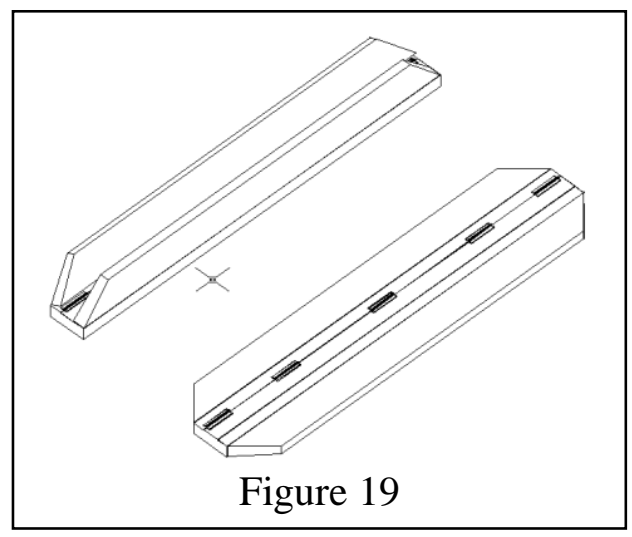

- The metal Arcades foldable "wings", can be plied as shown in (Fig 20) to ease the replacement and/or servicing operations needed to be done.

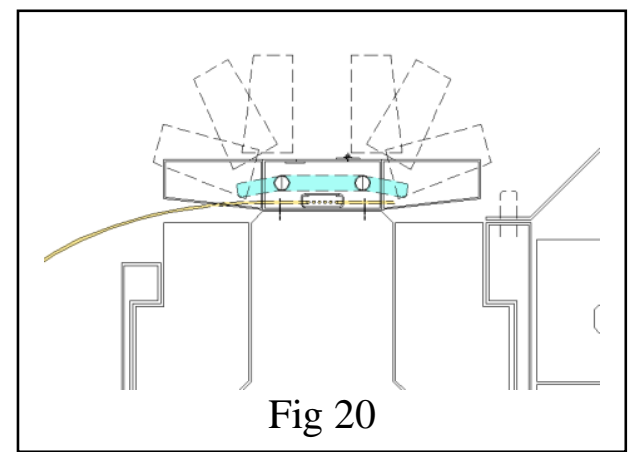

\section{8) Sequential steps for maintenance and servicing process"}

The following steps are sequentially carried out for maintenance and replacement works:

A) Concerning (VAF) “Ventilation, Air Conditioning and Filtration" unit:-

$\underline{A 1}$ - The flapping blades "LFBs", beneath the (VC-1) unit, are turned around their longitudinal axis, to get into "closed state".

$\underline{\boldsymbol{A 2}}$ - Activation of "Air-exhaust tubular ducts" beneath the (VC-1) unit.

A3 - Damper connected to the main ducting system is closed.

$\underline{A 4}$ - The "hut" above (VC-1) unit is removed, after disconnecting it from the "Flexible Duct" connected to the main ducting system.

$\underline{A 5}$ - The Metal Arcades walkways wings are folded (if needed) to ease the replacement and service operations.

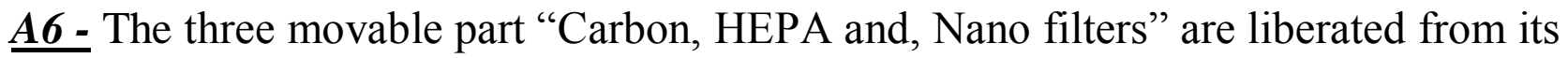
fixing means.

$\underline{A 7}$ - The Winch crane, moving back and forth by its car running and hanged from its railway, is then used to help the replacement process of Carbon, HEPA and, Nano filters.

Note:- concerning potentially high contaminated laboratories environments:-

It is important to take an intensive and serious care of having a hard plastic bag 
ready to contain immediately the replaced filters, eliminating the chance of airborne contaminants to be spread in the air.

$\underline{A 8}$ - After replacement of filtering units, the hut is installed and fixed firmly above the "new" units, and then connected to the main ducting system through the flexible duct.

Note:- The filtering units are dropped directly from a sterilized, hard plastic bag into the (VC-1) unit, preventing any potential accumulation of outside air borne pollution.

A9 - The activation of "Air-exhaust tubular ducts" will be kept turned on for a short period of time.

A10- Damper connecting the (VAF) unit to the main ducting system through the flexible duct is opened.

A11- The flapping blades "LFBs", beneath the (VC-1), are turned to the "open state". A12- Activation of "Air-exhaust tubular ducts" is turned off.

\section{$\underline{B}$ Concerning (LF) - "Light fixture" unit:-}

$\underline{B 1}$ - The movable part (PL-2) embracing all replaceable parts is liberated from its fixing means connected to part (PL-1), and disconnected from its power sources and control means.

$\underline{B 2}$ - The Winch crane is then used for the elevation of part (PL-2).

$\underline{B 3}$ - There are two alternatives for handling part (PL-2), it may be replaced completely, or serviced by having its "lamps" replaced.

$\underline{B 4}$ - The new or replaced part (PL-2) is put back in part (PL-1), re-fixed in its place, and connected to power sources and control wiring

\section{Conclusions:}

- The competitive pressures and changing research activities require organizations to be as flexible as possible. The paper showed that the system discussed, demonstrates a practical and flexible solution. Its grants laboratories organizations the ability to reaccommodate their research laboratories layouts, depending on changes needed by new research projects requirements, inexpensively and, with minimum costs

- The suggested technique is designated to be applied to laboratory areas in need for constant and high level of dust free, and sterilized interior zone, along with the preservation of sustainability of environmental laboratory enclosure areas (e.g., special degree of electronic and bio labs, such as "BSL-4")

- Concerning "Sequential steps for maintenance and servicing process". It is clear, till the last step, that the process of replacement and maintenance is performed without any obstruction to the ongoing research "workflow", eliminating any exposure risk of laboratory environmental enclosure conditions. 


\section{References:}

[1] Brian Griffin /Laboratory Design Guide/Architectural Press (Oxford - London) / Third edition / UK / 2005

[2] Stephen A. Kliment /Research Buildings/ John Wiley \& Sons / -- / USA / 2001

[3] SAFETY HANDBOOK - SCHOOL OF CHEMICAL SCIENCES - DUBLIN CITY UNIVERSITY / 2001-2002

[4] Stanford Laboratory Standard \& Design Guide / Stanford University / USA / 10-2003

[5] LABORATORIES FOR THE 21ST CENTURY : BEST PRACTICES U.S. Department of Energy - Energy Efficiency and Renewable Energy - Federal Energy Management Program -2004

[6] Laboratory Biosafety Guidelines / by Health Canada prior to the announcement of the establishment of the Public Health Agency of Canada on September 24, 2004.

[7] The Laboratory Biosafety Guidelines: Health Canada / 3rd Edition / 2004

[8] Microbiological and Biomedical Laboratories - Colorado State University / Regulatory Compliance Office (RCO) / 2005

[9] LABORATORY SAFETY DESIGN GUIDE, GENERAL REQUIREMENTS FOR LABORATORIES - University of Washington / USA / 04-2005

[10] IAEA Technical Reports Series No.292, IAEA, Vienna IAEA, Design and Operation of Off Gas Cleaning and Ventilation Systems in

[11] Facilities Handling Low and Intermediate Level of Radioactive Material .

[12] IAEA Technical Reports Series No.292, Vienna

[13] IAEA Safety series 48 - part 5.1. / part 5.3. / part 5.4. / part 5.5.

[14] Design Guide for Basic and Intermediate Level radioisotope LaboratoriesAtomic Energy Control Board's Regulatory Guide R-52 (USA)

[15] National Institute of Health, Publication No. 86-23

[16] NFPA 91 Standard for the Installation of Blower and Exhaust Systems

\section{Acronyms:}

MHB Metal, stainless steel - $\underline{\text { Hollow }}$ Boxes

LF $\quad \underline{\text { Light }}$ Fixture

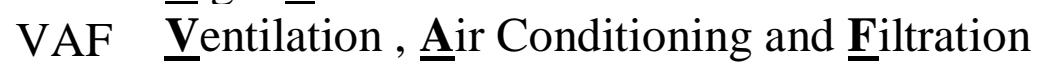

LFB $\underline{\text { Longitudinal }}$ Flapping $\underline{\text { Blades }}$

HEPA $\underline{\text { High }} \underline{\text { Efficiency }} \underline{\text { Particulate }} \underline{\text { Air (filter) }}$ 